04

\title{
Динамика начальной фазы искрового и диффузного разрядов в воздухе в промежутке острие-плоскость при различных параметрах острийного электрода
}

\author{
(C) А.А. Тренькин, К.И. Алмазова, А.Н. Белоногов, В.В. Боровков, Е.В. Горелов, И.В. Морозов, С.Ю. Харитонов
}

Российский Федеральный ядерный центр, Всероссийский научно-исследовательский институт экспериментальной физики,

607190 Саров, Россия

e-mail: alexey.trenkin@gmail.com

(Поступило в Редакцию 9 августа 2018 г.)

\begin{abstract}
Исследована динамика начальной фазы разряда в воздухе атмосферного давления в промежутке острие-плоскость при различных параметрах острийного электрода и длинах межэлектродного промежутка. В экспериментах в зависимости от длины межэлектродного промежутка реализовывались искровой или диффузный разряды. С использованием метода теневого фотографирования установлено, что при всех использованных в экспериментах электродах каналы разряда представляют собой совокупность множества микроканалов, развивающихся от острия и замыкающих разрядный промежуток.
\end{abstract}

DOI: 10.21883/JTF.2019.04.47305.309-18

\section{Введение}

Изучение импульсных разрядов в плотных газах, несмотря на продолжительную историю, остается актуальной задачей. Востребованность таких исследований обусловлена, с одной стороны, широким практическим использованием таких разрядов, а с другой - богатым разнообразием протекающих физических процессов и сложностью диагностики параметров разрядов, особенно на коротких временах.

Одним из вопросов, представляющих интерес для исследования, является наличие микроструктуры токовых каналов, первоначально зарегистрированной по их автографам на поверхности электродов [1-15]. Микроструктура представляет собой совокупность большого количества микрократеров, распределенных по сечению автографа. Оптическими и электронно-оптическими методами внутренняя микроструктура разряда была неразрешима [1-4,7,12-15].

В этой связи долгое время оставался открытым вопрос о наличии нитевидных каналов в объеме разрядного промежутка. Это было обусловлено, во-первых, сложностью регистрации слабо контрастирующих каналов микронной толщины на наносекундных временах, а вовторых, определенными сомнениями в возможности существования каналов микронного диаметра вследствие их неизбежного радиального ионизационного расширения $[16,17]$.

Вместе с тем проведенные недавно исследования искрового разряда с использованием системы регистрации на основе метода теневого фотографирования позволили установить наличие микроканалов, замыкающих межэлектродный промежуток [18]. Полученные результаты стимулируют дальнейшее изучение динамики импульсных разрядов в плотных газах. Так, например, акту- альными являются вопросы о фазе возникновения микроканалов, о наличии микроструктуры в других типах разрядов и ее зависимости от внешних факторов.

Целью настоящей работы является исследование начальной фазы разряда в воздухе атмосферного давления в промежутке острие-плоскость с использованием теневого и обычного фотографирования при различных параметрах острийного электрода и длинах межэлектродного промежутка.

\section{Экспериментальная аппаратура и методика}

Эксперименты проводились на стенде, включающем генератор импульсов напряжения (ГИН), кабельную линию, разрядный промежуток, диагностическую аппаратуру и систему синхронизации [18].

Генерация импульсов напряжения обеспечивалась коммутацией заряженной емкости на кабельную линию. Амплитуда напряжения на выходе ГИН составляла $25 \mathrm{kV}$, полярность напряжения - положительная. Кабельная линия с волновым сопротивлением $50 \Omega$ имела длину 7 m и нагружалась на разрядный промежуток.

В экспериментах использовались несколько осесимметричных острийных электродов, отличающихся формой поверхности и материалом (см. таблицу).

В качестве плоского электрода использовался электрод, изготовленный из алюминиевого сплава, с рабочей частью, близкой по форме к шаровому сегменту диаметром $4.5 \mathrm{~cm}$ толщиной $1.5 \mathrm{~cm}$.

В экспериментах регистрировались напряжение и ток на выходе ГИН. Измерение напряжения $U$ осуществлялось емкостным делителем, тока $I-$ резистивным шунтом. Регистрация напряжения и тока выполнялась цифровым осциллографом. 
Параметры острийных электродов

\begin{tabular}{l|c|c|c|c}
\hline Номер электрода & 1 & 2 & 3 & 4 \\
\hline Длина, mm & 50 & 40 & 19 & 40 \\
\hline Диаметр, mm & 15 & 10 & 36 & 14 \\
\hline $\begin{array}{l}\text { Угол при вершине } \\
\text { острия, grad }\end{array}$ & 80 & 60 & 0.15 & 0.1 \\
\hline Радиус кривизны, mm & 0.2 & 0.19 & $\begin{array}{c}\text { нлюржавеющая } \\
\text { сталь }\end{array}$ & $\begin{array}{c}\text { нержавеющая } \\
\text { сталь }\end{array}$
\end{tabular}

Система скоростной оптической регистрации включала в себя источник зондирующего излучения (лазер), объектив и цифровую электронно-оптическую камеру [18]. Плоскопараллельный пучок лазерного излучения, проходя через область разряда перпендикулярно оси электрода-острия, регистрировался электроннооптической камерой. Изображение разрядного промежутка переносилось на цифровую камеру с десятикратным увеличением. Система регистрации обеспечивала пространственное разрешение не хуже $5 \mu \mathrm{m}$. Размер поля зрения системы оптической регистрации составлял $1.6 \mathrm{~mm}$ вдоль оси разрядного промежутка и столько же в поперечном направлении.

В качестве источника зондирующего излучения использовался твердотельный лазер с длиной волны $532 \mathrm{~nm}$. Максимальная энергия в импульсе около $25 \mu \mathrm{J}$. Длительность импульса на полувысоте составляет $6 \mathrm{~ns}$, джиттер - $1.5 \mathrm{~ns}$. В области формирования разряда поперечный размер лазерного пучка составлял примерно $1 \mathrm{~cm}$ и имел гауссов профиль.

Съемка электронно-оптической камерой велась в однокадровом режиме с экспозицией $40 \mathrm{~ns}$. Для визуализации начальной стадии разряда момент запуска лазера выбирался ближе к закрытию электронно-оптического затвора. Интервал времени между окончанием лазерного импульса и закрытием затвора составлял около $10 \mathrm{~ns}$. При этом значительная часть времени экспозиции опережала начало формирования разряда. На входе электронно-оптической камеры располагались светофильтры, обеспечивающие пропускание только лазерного излучения.

Описанная система оптической регистрации применялась и для съемки собственного свечения разряда. В этом случае не использовались лазер и светофильтры.

В ряде экспериментов помимо скоростной съемки осуществлялась съемка интегрального свечения разряда в близком ракурсе цифровым фотоаппаратом.

Варьированием момента запуска ГИН относительно запуска скоростной оптической системы регистрации обеспечивалась визуализация различных стадий разрядного процесса. Временная привязка кадра в каждом импульсе осуществлялась по осциллограммам напряже- ния и тока разряда, контрольным сигналам лазера и цифровой электронно-оптической камеры с учетом длин электрических и световых линий. Привязка тенеграммы определялась моментом пуска лазера, а длительность кадра - длительностью импульса лазера. Привязка кадра собственного свечения разряда определялась моментом закрытия затвора электронно-оптической камеры.

\section{Экспериментальные результаты и их обсуждение}

При приходе волны напряжения по кабельной линии на разрядный промежуток вначале происходил рост напряжения, затем резкий спад и одновременный рост тока в разрядной цепи, обусловленные пробоем промежутка. В зависимости от межэлектродного зазора реализовывались два типа разряда - искровой и диффузный, при зазорах 1.5 и $18 \mathrm{~mm}$ соответственно. В обоих случаях напряжение пробоя составляло примерно $35 \mathrm{kV}$.

В случае искрового разряда после пробоя промежутка в разрядной цепи возникал затухающий колебательный процесс. Длительность полуволны тока составляла $0.5 \mu \mathrm{s}$, амплитуда тока и время его затухания

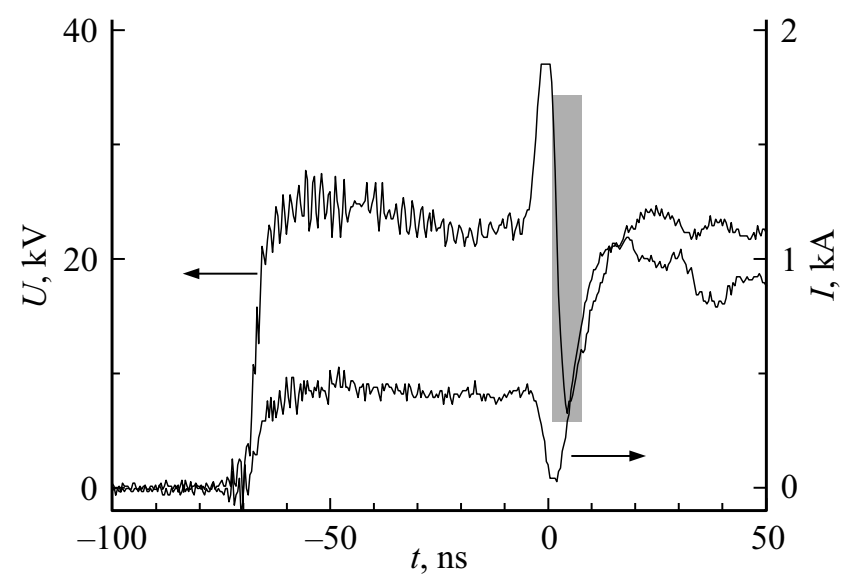

Рис. 1. Фрагмент осциллограммы напряжения $U$ и тока $I$ искрового разряда. Серым прямоугольником обозначен интервал теневой съемки. 


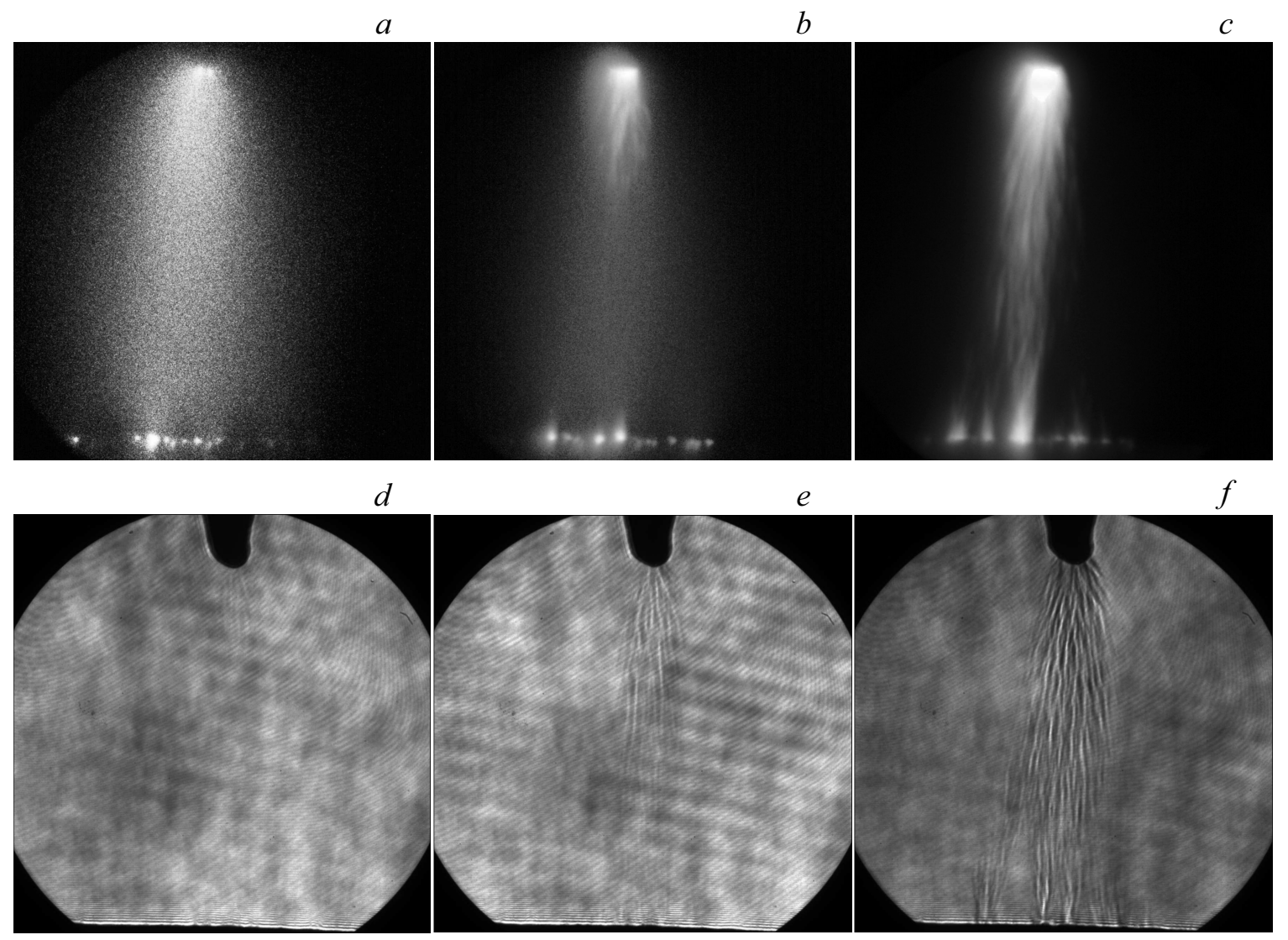

Рис. 2. Кадры собственного свечения искрового разряда $(a-c)$ и тенеграммы $(d-f)$ в различные моменты времени относительно пробоя $(a-4, b-7, c-12, d-2, e-5, f-8 \mathrm{~ns})$ для электрода № 4 (находится сверху).

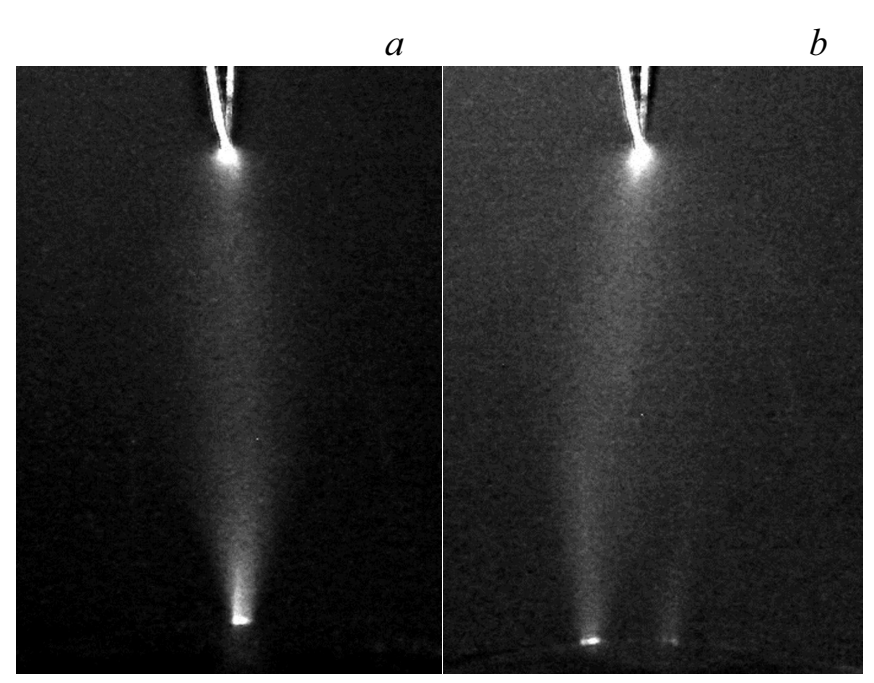

Рис. 3. Интегральные фотографии различных форм свечения разряда для электрода № 4: $a-$ одноканальная, $b-$ многоканальная.

соответственно $1.5 \mathrm{kA}$ и $2 \mu \mathrm{s}$. Заметных отличий в осциллограммах искрового разряда для различных типов электродов не обнаружено.
На рис. 1 представлен фрагмент характерных осциллограмм тока и напряжения искрового разряда в начальной фазе с обозначением временного интервала теневой съемки в этом импульсе.

На рис. 2, $a-c$ представлены кадры собственного свечения искрового разряда, а на рис. $2, d-f$ примерно соответствующие им по времени тенеграммы для электрода № 4.

В результате регистрации собственного свечения искрового разряда установлено, что начальной фазой свечения является возникновение диффузного канала на временах 0-5 ns, на фоне которого последовательно формируются: катодные пятна на поверхностности плоского электрода; каналы, развивающиеся от острийного электрода и замыкающиеся на катодные пятна на временах 5-10 ns; искровой канал. Определенные по фотографиям собственного свечения разряда диаметр диффузного канала составляет не более $0.8 \mathrm{~mm}$, диаметры катодных пятен находятся в интервале от 20 до $100 \mu \mathrm{m}$. Отметим, что диффузный канал присутствует и на более поздних стадиях разряда (рис. 2,c), однако почти не различим на фотографиях вследствие относительно высокой интенсивности свечения прианодной области и каналов. Схожая динамика формирования разряда наблюдалась в работе [12]. 


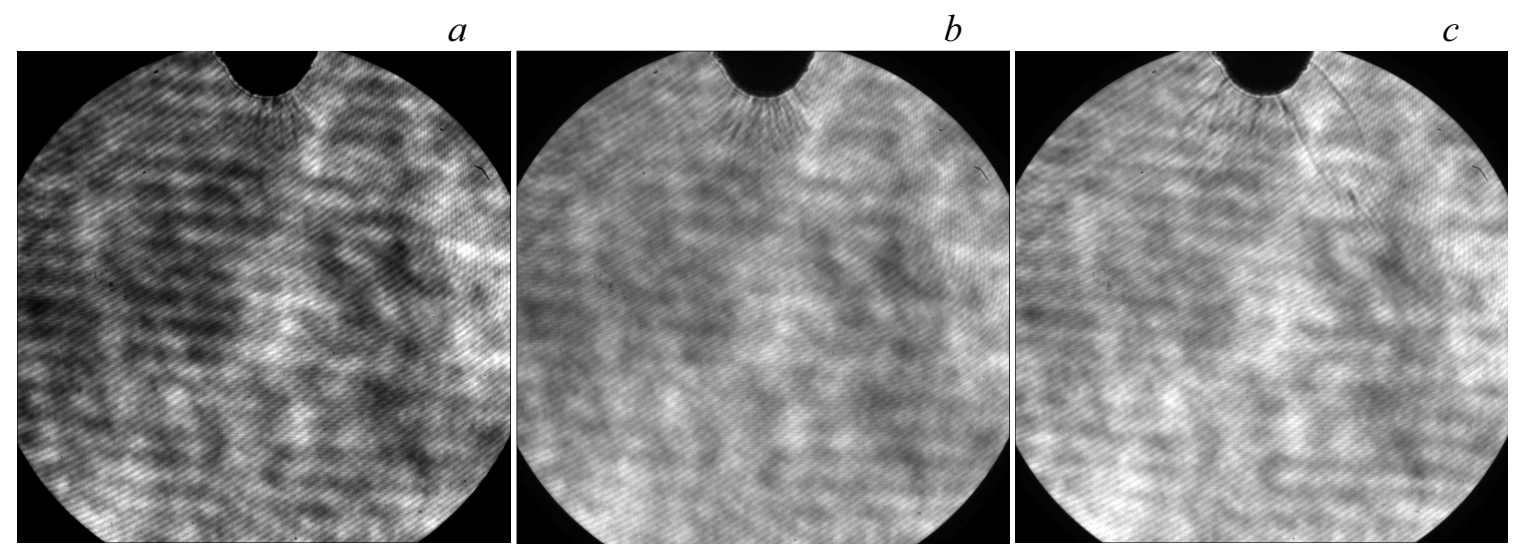

Рис. 4. Тенеграммы диффузного разряда в различные моменты времени относительно пробоя $(a-30, b-44, c-70 \mathrm{~ns})$ для электрода № 3 .

Кадры теневой съемки свидетельствуют, что разряд развивается в микроканальной форме и представляет собой пучок большого числа микроканалов. Раньше всего микроканалы регистрируются вблизи острийного электрода (рис. $2, d$ ), затем во всем промежутке (рис. 2,e, f). При этом на плоском катоде наблюдаются области привязки нескольких соседних микроканалов (рис. 2,f). Размеры таких областей, определенные по тенеграммам, близки к размерам катодных пятен на кадрах свечения и, по-видимому, могут быть отождествлены с ними.

Область, занимаемая микроканалами, в большинстве случаев близка по форме к усеченному конусу с основанием на плоском электроде. Поперечные размеры этой области составляют 200-300 $\mu$ в вблизи острия, 300-400 $\mu \mathrm{m}$ в центральной части промежутка и до $700 \mu \mathrm{m}$ вблизи плоского электрода. По-видимому, область присутствия микроканалов соответствует ярко светящейся области искрового разряда, идентифицируемой на интегральных фотографиях как керн [11-14].

Диаметры микроканалов в начальной фазе (рис. $2, d-f$ ) составляют около $15 \mu \mathrm{m}$. Микроструктура наблюдается на тенеграммах, начиная с фазы диффузного свечения разряда (рис. 2, $a, d$ ). В отсутствие подсвечивающего лазерного излучения микроканалы на фотографиях свечения разряда не различимы (рис. 2,a-c). Размеры диффузного свечения разряда в области острия и в центральной части промежутка, как правило, превосходят размеры области, занимаемой микроканалами.

В дальнейшем диаметр микроканалов растет, они начинают взаимодействовать друг с другом, после чего структура канала на тенеграммах становится хаотичной, отдельные протяженные микроканалы не регистрируются, а на границе канала разряда формируется ударная волна [18].

Описанная выше картина развития разряда наблюдается при всех использованных в настоящей работе электродах.

Близкая динамика процессов в разряде с более тонким острийным электродом наблюдалась в [19-21] с использованием теневого и интерференционного методов, однако, в отличие от настоящих результатов, микроструктура разряда там была менее выраженной.

При формировании диффузного типа разряда использовались электроды № 3 и 4. При этом от импульса к импульсу реализовывалась одна из двух его форм одноканальная и многоканальная. Интегральные фотографии указанных форм представлены на рис. 3 .

При использовании электрода № 3 вероятность реализации объемной и многоканальной форм составляла примерно 40 и 60\%; при использовании электрода № 4 30 и $70 \%$ соответственно.

В этой связи следует указать на работы $[8,22,23]$, где в схожей геометрии, но при значительно превосходящих зазорах, были детально изучены структура свечения и электрические характеристики разряда в широком диапазоне радиуса кривизны острия электрода. Помимо этого там была зарегистрирована микроструктура автографа токового канала на поверхности плоского электрода [8].

Для использованных электродов и форм диффузного разряда осциллограммы напряжения и тока не имели заметных отличий. После пробоя промежутка напряжение на выходе генератора спадало экспоненциально, время затухания составляло около $T=500 \mathrm{~ns}$. Ток в разрядной цепи имел колебательный затухающий характер, что обусловлено перезарядкой кабельной линии. Емкость разрядной цепи определялась емкостью кабельной линии, величина которой составляет примерно $C=500 \mathrm{pF}$. Указанные данные позволяют оценить сопротивление разряда на уровне $R=T / C=1 k \Omega$. В этом случае ток разряда при амплитудном значении напряжения составляет $I=U / R=35 \mathrm{kV} / 1 \mathrm{k} \Omega=35 \mathrm{~A}$, что существенно меньше тока перезарядки кабельной линии.

При теневой съемке диффузного разряда поле обзора было таким же, как и для искрового разряда, поэтому в кадр попадала только область вблизи острийного электрода. В ряде экспериментов одновременно осуществлялась сьемка интегрального свечения разряда.

На рис. 4 представлены тенеграммы диффузного разряда для электрода № 3 в различные моменты вре- 
мени относительно пробоя. На тенеграммах, начиная с 20-30 ns, регистрируются множество микроканалов отходящих от острия (рис. $4, a)$.

С течением времени микроканалы развиваются вглубь промежутка (рис. 4,b) и, начиная примерно с 60-й ns, становятся отчетливо заметны границы отдельных каналов разряда (рис. 4,c). Регистрируемая на тенеграммах канальная структура разряда хорошо коррелирует с его интегральными изображениями при одновременной съемке. При этом на кадрах интегрального свечения диффузного разряда микроструктура была неразличима.

Аналогичные результаты получены и для диффузного разряда с электродом № 4. В завершение отметим, что более позднее относительно искрового разряда появление микроканалов на тенеграммах может являться следствием существенно меньшего тока диффузного разряда, который за малые времена не способен обеспечить высокие градиенты плотности газа, регистрируемые на теневых фотографиях. Этой же причиной можно объяснить и отсутствие микроструктуры на тенеграммах в периферийных областях диффузного канала искрового разряда.

\section{Заключение}

Представлены результаты экспериментальных исследований динамики начальной фазы искрового и диффузного разрядов в воздухе в промежутке острие-плоскость при различных параметрах острийного электрода.

Получены кадры свечения и тенеграммы начальных стадий искрового разряда при межэлектродном зазоpe $1.5 \mathrm{~mm}$. На фотографиях свечения условно выделены следующие последовательные стадии разряда: формирование диффузного канала и катодных пятен на поверхностности плоского электрода на временах 0-5ns; формирование каналов, развивающихся от острийного электрода и замыкающихся на катодные пятна на временах 5-10 ns; формирование искрового канала.

На теневых фотографиях искровой разряд регистрируется в виде множества микроканалов, замыкающих разрядный промежуток. Микроканалы начинают наблюдаться вблизи острийного электрода в стадии диффузного свечения. На поверхности плоского электрода фиксируются области привязки нескольких соседних микроканалов, отождествляемые с катодными пятнами.

Приведены результаты исследований диффузного разряда при межэлектродном расстоянии $18 \mathrm{~mm}$, реализующегося как в одноканальной, так и в многоканальной форме.

Впервые получены тенеграммы диффузного разряда, устанавливающие наличие микрокроструктуры в межэлектродном промежутке. Микроструктура регистрируется, начиная с 20-30 ns от начала пробоя, и представляет множество микроканалов, отходящих от острия. С течением времени микроканалы развиваются вглубь промежутка и, начиная примерно с 60-й ns, регистрируются границы отдельных каналов разряда. Установлено, что канальная структура разряда, регистрируемая на тенеграммах, хорошо коррелирует с интегральными изображениями свечения разряда.

Получено, что для всех исследованных типов разрядов микроканальная структура присутствует вне зависимости от параметров использованных в экспериментах острийных электродов.

Авторы благодарны В.И. Карелину за активную поддержку работы.

\section{Список литературы}

[1] Карелин В.И., Тренькин А.А. // ЖТФ. 2008. Т. 78. Вып. 3. C. 29-35.

[2] Karelin V.I., Trenkin A.A. Microchannels in Atmospheric Pressure Pulsed Discharges. In book „Runaway Electrons Preionized Diffuse Discharges“ / Ed. By V.F. Tarasenko. Nova Publishers, 2014.

[3] Буранов С.Н., Горохов В.В., Карелин В.И., Павловский А.И., Репин П.Б. // Квантовая электроника. 1991. Т. 18. Вып. 7. С. 891-893.

[4] Буранов С.Н., Горохов В.В. и др. Микроструктура токовых каналов и убегание электронов в высоковольтных диффузных разрядах атмосферного давления. Исследования по физике плазмы: Сб. науч. тр. / Под ред. В.Д. Селемира, А.Е. Дубинова. Саров, 1998. С. 39-67.

[5] Репин П.Б., Репьев А.Г. Исследование пространственной структуры токовых каналов высоковольтного диффузного разряда в промежутке проволочка-плоскость. Сборник научных трудов / Под общей редакцией В.Д. Селемира, А.Е. Дубинова. Саров: ФГУП РФЯЦ-ВНИИЭФ, 2003. C. $143-172$.

[6] Автореф. канд. дис. Лай Гуйю. Системы импульсного электропитания и возбуждение на их основе диффузного разряда. М.: МИФИ, 2004.

[7] Перминов А.В., Тренькин А.А. // ЖТФ. 2005. Т. 75. Вып. 9. C. $52-55$.

[8] Репьев А.Г., Репин П.Б., Покровский В.С. // ЖТФ. 2007. Т. 77. Вып. 1. С. 56-62.

[9] Балданов Б.Б. // Прикладная физика. 2012. № 1. С. 64-67.

[10] Trenkin A.A., Karelin V.I., Fedoseev I.G. // High Voltage Engineer. 2014. Vol. 40. N 7. P. 2211-2216.

[11] Тренькин А.А., Карелин В.И., Шибитов Ю.М. // Известия вуз. Физика. 2014. Т. 57. № 12/2. С. 284-289.

[12] Бакшт Е.Х., Блинова О.М., Ерофеев М.В. идр. // ФП. 2016. T. 42. № 9. C. 859-870.

[13] Карелин В.И., Тренькин А.А., Шибитов Ю.М., Блинова О.М., Ясников И.С. // ЖТФ. 2016. Т. 86. Вып. 10. С. 54 57.

[14] Карелин В.И., Тренькин А.А., Шибитов Ю.М., Блинова О.М., Ясников И.С. // ЖТФ. 2017. Т. 87. Вып. 9. С. 14111415.

[15] Buranov S.N., Gorokhov V.V., Karelin V.I., Repin P.B., Rep'ev A.G., Trenkin A.A. Generation of high-energy electrons and $X$-rays in high-voltage diffuse discharges at atmospheric pressure with interelectrode gaps up to tens of centimeters. In book „Generation of Runaway Electron Beams and $X$-ray in high pressure gases". Vol. 1. Techniques and Measurements. Editors: V.F. Tarasenko. NY.: Nova Publishers, 2016. 
[16] Базелян Э.М., Райзер Ю.П. Искровой разряд. М.: Изд-во МФТИ, 1997. $320 \mathrm{c.}$

[17] Тренькин А.А., Карелин В.И. // ЖТФ. 2006. Т. 76. Вып. 2. C. $52-56$.

[18] Алмазова К.И., Белоногов А.Н., Боровков В.В., Горелов Е.В., Морозов И.В., Тренькин А.А., Харитонов С.Ю. // ЖТФ. 2018. Т. 88. Вып. 6.

[19] Паркевич Е.В., Ткаченко С.И., Агабонов А.В. идр. // ЖЭТФ. 2017. Т. 151. Вып. 4. С. 627-636.

[20] Медведев М.А., Паркевич Е.В., Хитько М.А. идр. Особенности формирования плотной прианодной плазмы при наносекундном разряде в воздухе атмосферного давления // Сб. тр. конф. „Импульсная сильноточная вакуумная и полупроводниковая электроника“. М.: ФГБУН Физический институт им. П.Н. Лебедева РАН, 2017. С. 28-30.

[21] Медведев М.А., Паркевич Е.В., Хитько М.А. идр. Нитевидная микроструктура токовых каналов в искровой стадии наносекундного разряда // Сб. тр. конф. „Импульсная сильноточная вакуумная и полупроводниковая электроника“. М.: ФГБУН Физический институт им. П.Н. Лебедева PAH, 2017. C. 41-44.

[22] Репьев А.Г., Репин П.Б., Данченко Е.Г. // ЖТФ. 2005. Т. 75. Вып. 7. С. 60-64.

[23] Репьев А.Г., Репин П.Б., Данченко Е.Г. // ЖТФ. 2008. Т. 78. Вып. 7. С. 40-47. 